\title{
MÚSICA INFORMAL: PERSPECTIVAS ATUAIS DO CONCEITO ADORNIANO
}

\author{
Eduardo Socha* \\ esocha@gmail.com
}

RESUMO O ensaio "Vers une musique informelle" (1961) é uma das mais conhecidas (e talvez mal compreendidas) contribuições da reflexão musical de Adorno, certamente um dos maiores legados de sua filosofia da música. Este artigo procura, em um primeiro momento, especificar o sentido crítico da contribuição conceitual de Adorno, que visava à superação dos impasses e da alternativa entre pensamento motívico-temático e pensamento serial nas práticas composicionais de época. Em seguida, descreve a intenção propositiva de Adorno ao encaminhar uma "teoria material das formas", teoria que, na realidade, havia sido concretizada na monografia sobre Mahler, publicada no ano anterior ao ensaio. Por fim, busca evidenciar a atualidade do conceito de música informal, questionando, por um lado, a leitura de Fredric Jameson $e$, por outro, examinando brevemente os procedimentos de dois compositores contemporâneos cujo teor remete ao conceito adorniano: Helmut Lachenmann e Wolfgang Rihm.

Palavras-chave Adorno, filosofia da música, música informal, tematismo, serialismo.

ABSTRACT Adorno's essay "Vers une musique informelle" (1961) is one of the most well-known (and maybe one of the most misunderstood) contributions of his musical thought and also considered one of the most significant legacies of his philosophy of music. Initially, this article intends to specify the critical

* Universidade de São Paulo, São Paulo/SP - Brasil. Artigo recebido em 31/08/17. Aceito em 21/10/17. 
sense of Adorno's conceptual contribution, which aimed the overcoming of the avant-garde compositional stalemate and the alternative between motivicthematic thought and serialistic thought, at the time. Then, it describes the intention put forward by Adorno in his "material theory of forms", a theory that had been fully developed in the monograph on Mahler, published just one year before the essay. Finally, the article tries to show some of the contemporary implications of the concept of informal music, by questioning, on the one hand, Fredric Jameson's interpretation of the concept, and, on the other hand, briefly examining the methods of two contemporary composers that seemingly set this concept in motion: Helmut Lachenmann and Wolfgang Rihm.

Keywords Adorno, philosophy of music, informal music, motivic-thematic thought, serialism.

\section{Introdução}

Podemos afirmar que o ensaio de Adorno sobre o conceito de música informal - nas palavras de Wiggershaus (2002, p. 554), a "obra de teoria da música mais importante depois de Philosophie der neuen Musik" - consubstancia a rejeição programática àquilo que o filósofo vinha qualificando desde 1949 como a "negação da temporalidade" na nova música. Com efeito, em Vers une musique informelle, constatamos o esforço de Adorno para esclarecer os conceitos de material, forma, aparência, expressão e tempo musical, à luz dos desenvolvimentos do serialismo no final dos anos 1950. Sua interlocução com o musicólogo Heinz-Klaus Metzger nesse período praticamente balizou as três conferências de 1961 proferidas em Kranichstein-Darmstadt, que deram origem ao conhecido ensaio. O manifesto de uma música informal - ou música "a-serial", conforme a sugestão de Metzger ${ }^{1}$ - marcava o retorno do filósofo ao círculo dos Ferienkurse (cursos de verão) de Darmstadt, após a polêmica provocada pelas suas críticas ao serialismo, sobretudo no ensaio $O$ envelhecimento da nova música, de 1954 - críticas estas que foram rebatidas em 1957 pelo próprio Metzger em $O$ envelhecimento da "Filosofia da nova música". ${ }^{2}$

1 Aserielle, termo tomado de Metzger como equivalente de "música informal": "einen der exponiertesten Begriffe, den einer informellen oder, wie Metzger es nannte, aseriellen Musik" (Adorno, Vers une musique informelle, GS 16, p. 495). As traduções das citações deste artigo foram realizadas por mim, a não ser quando expressamente indicado.

2 Para uma análise pormenorizada da polêmica e da correspondência entre Adorno e Metzger, bem como das condições que marcaram o retorno de Adorno ao círculo de Darmstadt, tomo a liberdade de remeter o leitor ao capítulo 5 da tese de doutorado Tempo musical em Theodor W. Adorno (Socha, 2015). 
Por não esconder uma deliberada dimensão propositiva, Vers une musique informelle é um texto heterodoxo na ensaística de Adorno: logo no início do texto, ao justificar o título em francês, o autor declarava "gratidão à nação para a qual a tradição da vanguarda é sinônimo da coragem civil (Zivilcourage) para produzir manifestos" (Adorno, Vers une musique informelle, GS 16, p. 495). Devemos ter em mente que, ainda no final dos anos 1950, o serialismo era considerado o método "historicamente necessário e eticamente responsável" entre os compositores da vanguarda após a Segunda Guerra, ou seja, para essa geração, o paradigma da série havia se transformado em "força de lei" da nova música. O tom de manifesto de Vers une musique informelle visava alertar, nesse sentido, para a estaticidade inscrita no pensamento serial e para as incongruências nas obras correspondentes do período: "Sob o aspecto da consciência do tempo, a prática contemporânea sinaliza incongruências (Mißverhältnisse) que tornam urgente uma revisão desses procedimentos" (Adorno, Vers une musique informelle, GS 16, p. 532). De todo modo, o estranhamento provocado pelo ensaio - uma das mais conhecidas e talvez mal compreendidas contribuições do pensamento musical de Adorno - não se deve tanto a seu conteúdo. Basicamente, Adorno retomava um conjunto de temas que já haviam sido trabalhados em ensaios como O envelhecimento da nova música (1954), Critérios da nova música (1957) ou Música e técnica (1958), a saber: o problema do nominalismo, ou seja, a rebelião das práticas composicionais contra a consolidação de formas universais que poderiam assegurar a ideia de sentido musical; a racionalização do material e a insuficiência da composição por parâmetros, que valorizava mais a nota individual e sua dimensão sensorial do que propriamente a relação entre notas; a necessidade de resgatar o caráter de aparência e as categorias de expressão e de sentido na produção das obras. No fundo, o verdadeiro estranhamento provocado pelo ensaio deve-se muito mais à maneira quase tética, proposicional, almejando uma intervenção urgente e insinuando, por assim dizer, um regime preceptivo de como compor, através do qual o autor daria o peso de um manifesto. ${ }^{3}$

3 Colabora para essa abordagem programática o fato de, em várias passagens, Adorno utilizar o futuro do pretérito ("música informal seria...", "música informal deveria...", "esta seria a tarefa primordial..."), alternadamente com asserções como: "a vanguarda exige uma música que pegue o compositor de surpresa [...] música informal é a ideia de algo não totalmente imaginado [...] a intenção não é reinstaurar composição temático-motívica como requisito indispensável [...] música informal se rebela contra fé extrema do material e organização absoluta [...] música informal não é neutralismo cultural, mas crítica do passado" etc. Raymond Geuss comenta a estranheza provocada pelo ensaio, em sua dimensão prática, sob a perspectiva hegeliana do "voo da coruja": "In particular dialectical philosophy could not be used for giving directions about how to act. Dialectic was precisely not supposed to be a form of Besserwisserei [...] There is something inherently odd about Adorno's project in 'Vers une musique informelle' of using a dialectical method to tell us where music must, could, might, or ought to go. Strictly speaking, a Hegelian dialectician should claim that the 'outcome' 
A primeira referência à expressão música informal encontra-se no pequeno artigo "Sobre a situação da composição na Alemanha" (1960), em que Adorno preconizava a existência de "reino almejado da liberdade, uma verdadeira musique informelle" (Adorno, Zweite Nachtmusik, GS 18, p. 138). Sem dúvida, o tom da três conferências que serviram de base para Vers une musique informelle afastava-se da vociferação performática de $O$ envelhecimento da nova música e se aproximava muito mais do tom conciliatório do ensaio Stravinsky: uma imagem dialética, escrito praticamente na mesma época, em 1962; neste segundo ensaio sobre Stravinsky, Adorno não parecia estar tão preocupado com um suposto revisionismo (em relação ao capítulo pouco indulgente, dedicado ao compositor, de Filosofia da nova música) mas visava, antes, denunciar a "pseudomorfose do tempo em espaço", procedimento que caracterizava o serialismo e que encontrava suas origens, segundo Adorno, em Stravinsky. Observamos aqui um curioso paralelo na estrutura argumentativa desses dois ensaios tardios, que merece ser explicitado. Ambos os textos começam com um esboço de autocrítica do autor: no caso de Stravinsky: uma imagem dialética (1962), com a breve reavaliação do procedimento de montagem e o reconhecimento da atribuição indevida de uma norma externa e um enunciado (Aussage) à aparência concreta da obra; no caso de Vers une musique informelle (1961), com impressões favoráveis sobre obras da "escola de Kranichstein-Darmstadt", a concordância de que aspectos tradicionais como campos de tensão e repouso, antecedente e consequente (a "retórica expressiva" ainda presente em Schoenberg) não mais constituem categorias a priori. ${ }^{4}$ Assim, podemos ter a impressão de que o autor estaria disposto a modificar suas posições iniciais ("não é possível afirmar que", "é preciso corrigir").

No entanto, logo após a breve concessão, Adorno sempre acrescenta um "no entanto" que absorve dialeticamente o momento de autocrítica, para então determinar com maior rigor suas posições precedentes. Essa estratégia retórica, presente nos dois ensaios, consiste, por assim dizer, em uma apurada superação, uma Aufhebung da autocrítica inicial (sob a forma de um "é necessário corrigir

of a conflict, tension, contradiction, etc. can be seen to be 'rational' or 'logical' only retrospectively." (Geuss, 1999 , p. 146). Todavia, o comentário de Geuss parece passar ao largo do propósito de intervenção social que subjaz ao projeto da teoria crítica.

4 Ver, no início desse segundo ensaio sobre Stravinsky, declarações conciliatórias como: "Man könne nicht, wie ich, den Scheincharakter des Kunstwerks gegen die Ideologie von Aussage, Echtheit und Eigentlichkeit verteidigen und dann doch den Schein dessen bezichtigen, daß er Schein sei" (Adorno, Vers une musique informelle, GS 16, p. 386); e em Vers une musique: "In Kranichstein habe ich einmal [...] geziehen mit der Frage: „Wo iset hier Vorder- und Nachsatz? « Das wäre zu berichtigen" (ADORNO, Vers une musique informelle, GS 16, p. 504, grifos meus). 
isso, mas mesmo assim..." ${ }^{\text {"5 }}$. Tal modulação traz a vantagem de expandir o campo das avaliações iniciais a respeito de Stravinsky e do serialismo, preservando seu núcleo crítico-conceitual e sua posição inicial. Se indicamos aqui tal estratégia, é para insistir no fato de que não há lugar para revisionismos conceituais em Adorno, a não ser para atualizações de ocasião. ${ }^{6}$ Vejamos como o autor utiliza, em Vers une musique informelle, a mesma estratégia argumentativa para refletir sobre as relações, à primeira vista de oposição e mútua exclusão, entre pensamento motívico-temático e pensamento serial: a nosso ver, o propósito maior de Vers une musique informelle consiste em oferecer um novo modo de compreensão dessas duas tradições aparentemente divergentes.

\section{Atematismo e serialismo: figuras dialéticas do tematismo?}

De início, notemos como Adorno descreve o percurso compositivo de Schoenberg em Vers une musique informelle: uma oscilação permanente entre os extremos do atematismo e do tematismo, entre a liberdade e a organização total. ${ }^{7}$ Com Erwartung op. 17, Schoenberg havia sentido que o trabalho motívicotemático prejudicaria o fluxo narrativo do monodrama, forçando a composição na direção do atematismo. Porém, na leitura de Adorno, essa abordagem atemática de Erwartung não cede ao simples acaso, à disposição arbitrária de notas, mas supera e conserva (aufhebt) o "espírito do trabalho motívico-temático" no interior da própria obra; ou seja, o atematismo radical de Erwartung transforma dialeticamente o próprio tematismo, alterando retrospectivamente a cadeia de

5 Tal efeito surge em Stravinsky, uma imagem dialética, na seguinte passagem: "Das Plausible dieser Einwände ist nicht zu unterschätzen. Aber sie vernachlässigen ein Zentrales. Etwas an Strawinskys Musik stimmt immanent nicht; »il y a quelque chose qui ne va pas «" (Adorno, Vers une musique informelle, GS 16, p. 387); ao passo que, em Vers une musique, após reconhecer a transitoriedade de "elementos expressivos tradicionais", certamente por influência do debate com Metzger, Adorno propõe a criação de "categorias equivalentes" a tais elementos, pois seriam "indispensáveis" à articulação formal (ADORNO, Vers une musique informelle, GS 16, p. 504).

6 Consideramos equivocada, nesse sentido, a difundida tese do "revisionismo" adorniano após a polêmica com Metzger, endossada por diversos comentadores; por exemplo, Iddon: "Metzger would hear nothing from Adorno that might approach a revision of his views until 1961, when Adorno presented 'Vers une musique informelle' at the Ferienkurse" (Iddon, 2013, p. 141, grifo meu) - ou ainda, Müller-Doohm na extensa biografia sobre Adorno: "Following this act of self-criticism as well as a revision of the concept of the composing subject, on the one hand, and the musical material, on the other, Adorno called for (in agreement with Metzger's 'aserial music') what for the first time he termed musique informelle" (Müller-Doohm, 2009, pp. 396-397); ou ainda Borio (2006). A lista de autores que insistem na ideia de revisionismo é considerável.

7 Tal oscilação tematismo-atematismo seria demonstrada com uma sequência cronológica de obras, iniciada com o Segundo quarteto op. 10, em especial o terceiro movimento (temático) e o quarto movimento (tendência para o atemático, que inaugura a atonalidade); a partir de então: terceira peça das Três peças op. 11 seria atemática; as Cinco peças op. 16, maior parte temáticas; Erwartung op. 17, totalmente atemática; Pierrot op. 21 e Quinteto op. 26, temáticas; Trio de cordas op. 45, atemático (Adorno, Vers une musique informelle, GS 16 , p. 500). 
relações anteriores e a totalidade de seu conceito. Depois de Erwartung, o conceito de tematismo passa a subsumir toda música - incluindo, por um efeito retroativo, o próprio monodrama de Schoenberg. Ou seja, o tematismo passa a integrar "complexos de autonomia relativa em um nexo geral (Zusammenhang) que se manifesta através de seus caracteres e de suas relações umas com as outras", indo além de similaridades e variações motívicas, indo além, inclusive, de um fundamento como "tema" (Adorno, Vers une musique informelle, GS 16, p. 515). Aprofundemos sob outro ângulo a análise desse aspecto problemático e suscetível a interpretações controversas, porém decisivo para o núcleo argumentativo do ensaio.

O que Adorno está afirmando com todas as letras, em Vers une musique informelle, é que o atematismo de Erwartung constitui uma nova figura dialética do conceito especulativo de tematismo, figura esta que nega o próprio princípio de tema. Os impulsos e as relações motívicas de Erwartung, embora não produzam temas, são descendentes, desvios dos temas (Abkömmlinge von Themen) (Adorno, Vers une musique informelle, GS 16, p. 515). A nova configuração do tematismo em Erwartung supera dialeticamente a noção tradicional de tema em suas relações motívicas elementares. Nessa nova configuração da composição temática, mas de aparência atemática - sob a qual deveríamos compreender as obras de Schoenberg e de Anton Webern do período médio -, constatam-se a dependência recíproca e a tensão entre momentos autônomos individuais (particularidades) e organização total (totalidade). Ocorre que, para Adorno, toda composição temática carrega consigo o telos de uma organização total. Em suma, com Erwartung, o conceito de tematismo absorve a composição atemática em seu telos da organização total.

Adorno não interrompe o argumento nesse ponto. Na sequência do texto de Vers une musique informelle, o autor passa a examinar a relação entre serialismo e tematismo, adotando a mesma estratégia para vincular o atematismo e o tematismo em Schoenberg. Projeta-se com isso um modo inédito de compreensão do serialismo. Segundo Adorno, no pensamento serial, o elemento de diferenciação (Differential) e o de integração (Integral) simplesmente se equivalem, a ponto de a construção (diferenciação) assumir a totalidade da obra por extrapolação: ${ }^{8}$ a integração de todos os parâmetros da nota individual não contém nada de qualitativamente distinto de sua totalidade (Adorno, Vers une musique informelle, GS 16, p. 516). Acontece que, para o filósofo, essa extrapolação do pensamento serial encontraria sua motivação no mesmo telos da organização total que já se

8 Para Adorno, o motivo seria um Zeitdifferential, "unidade diferencial para a criação de relações temporais" (Adorno, Zweite Nachtmusik, GS 18, p. 51). 
encontrava presente na composição motívico-temática, no tematismo. Desse modo,

pode-se compreender o pensamento serial não como contrário ao pensamento motívico-temático. A própria música serial originou-se (entstand aus) da totalidade do pensamento motívico-temático, isto é, da extensão desse princípio para incluir o tempo (Zeit) e o timbre (Farbe) [...] A diferença pode ser dita do seguinte modo: na composição serial, a unidade é pensada como um existente imediato (als unmittelbar Seiendes) e um oculto (Verborgenes); na composição motívico-temática, por outro lado, a unidade se define sempre como um devir (als Werdendes) e um revelado (Offenbarendes) (Adorno, Vers une musique informelle, GS 16, p. 516, grifos meus).

Adorno está propondo aqui uma leitura radicalmente diferente daquela que considera existir uma oposição irreconciliável entre tematismo e pensamento serial. Insistamos no que está sendo dito: o serialismo converte-se em figura oculta (Verborgenes) do tematismo, em figura estática e não mediada (unmittelbar) que se coloca como um puro existente (Seiendes). No percurso histórico de dominação da natureza da Aufklärung musical, o serialismo acaba integrando não apenas o timbre, mas o próprio tempo em sua totalidade sistemática - e, poderíamos acrescentar, também o acaso, como na $3^{a}$ sonata para piano, de Boulez, ou na Klavierstück 11, de Stockhausen - incorrendo consequentemente no arbítrio da pura stasis, rejeitando o caráter de aparência e bloqueando o próprio percurso histórico da totalidade (dinâmica) do tematismo, seu telos. Quando o Differential e o Integral se tornam equivalentes, como seria no caso do serialismo, então simplesmente não há mais tempo musical, apenas a transitoriedade empírica de eventos justapostos. ${ }^{9} \mathrm{O}$ pensamento de integração serial produz "uma disposição de elementos um após o outro no tempo (das zeitlich Aufeinanderfolgende) que nega a sucessividade (Sukzessivität) e sabota a responsabilidade com o devir (Werden)" (Adorno, Vers une musique informelle, GS 16, p. 518). A música passa, mas não desenvolve. Adorno não está reavaliando, portanto, suas considerações a respeito do serialismo como as que haviam sido apresentadas em $O$ envelhecimento da nova música, de 1954. Apenas inscreve a oposição entre música motívico-temática e música serial em uma noção dialética mais abrangente de relação (Adorno, Vers une musique informelle, GS 16, p. 519) - noção esta que seria a figura ulterior do tematismo.

Estaríamos enganados se acreditássemos que, através desse conceito especulativo de tematismo, Adorno realizaria a hipóstase da noção de relação em detrimento da nota individual. O próprio filósofo dissipa a conjectura: "não 
há notas sem relações, assim como relações sem notas" (Adorno, Vers une musique informelle, GS 16, p. 522). Fazer da "relação entre notas" um absoluto imediato, um "primeiro", seria o erro invertido da hipóstase da nota individual. Herbert Eimert, um dos principais defensores da música eletrônica, defendia em 1955, por exemplo, a precedência dos atributos acústicos do som sobre os demais aspectos da composição, precedência que apontaria para uma primazia ontológica da nota individual, independentemente de sua função ou relação. ${ }^{10}$ Para Adorno, entretanto, toda busca por um originário, por um "primeiro", seja na música ou na filosofia, estaria sentenciada ao anátema da reificação da consciência, ideologia (semelhante ao que contaminaria a fenomenologia de Husserl e Heidegger em sua obsessão pelo "elemento originário" na esteira de uma prima philosophia). Por outro lado, é difícil não enxergar o fundamento da reflexão musical adorniana no próprio trabalho motívico-temático, nessa dialética da Sukzessivität entre "nota individual" e "relação entre notas", sobretudo no contexto do princípio de "variação em desenvolvimento" (entwickelnde Variation). ${ }^{11} \mathrm{O}$ tematismo apresenta-se como a verdadeira "dessemelhança de um semelhante", a concretização dialética "do transcurso do tempo na substância musical". ${ }^{12}$ Ressaltemos a conclusão subjacente a Vers une musique informelle quanto ao conceito especulativo de tematismo: o conceito de tematismo incorpora e vai além do trabalho motívico-temático tradicional, além da escrita atemática e da técnica dodecafônica de Schoenberg, além do pensamento serial. O conceito supera dialeticamente tais abordagens composicionais como momentos internos de seu movimento. Como Adorno deixa claro na passagem destacada acima, o tematismo constitui pura e simplesmente, em sua unidade dialética, o próprio devir (Werden) e, portanto, a essência (Wesen) da arte musical.

\subsection{Música informal como "tendência"; o informe em Valéry}

É, portanto, no empenho para superar a alternativa entre pensamento motívico-temático tradicional e pensamento serial, através de uma interpretação especulativa do conceito de tematismo, que podemos compreender o projeto adorniano da música informal. Tanto para a Filosofia da nova música quanto

10 "Nunca ocorreria a um músico do século 19 definir a nota por sua altura, duração e intensidade. A nota era entendida em sua relação com outras notas e com a tensão dentro da estrutura do acorde. O século 19 não perguntava o que era a nota mas qual sua função [...] na música eletrônica-serial, por outro lado, tudo, até o último elemento da nota individual, está submetido à permutação serial" (Eimert, 1958, v. 1, pp. 6-8).

11 Conforme Jorge de Almeida, na filosofia de Adorno "qualquer elemento externo que viesse a impedir o fluxo da 'variação em desenvolvimento' significaria oposição à natureza essencialmente temporal do pensamento da música" (Almeida, 2007, p. 141).

12 "Thematische Arbeit, das Prinzip, das den abstrakten Zeitverlauf in der musikalischen Substanz konkretisiert, ist stets nur Ungleichheit eines Gleichen" (Adorno, Vers une musique informelle, GS 16, p. 506, nota 6). 
para Vers une musique informelle, a perspectiva dessa composição autêntica da liberdade esteve aberta "por volta de 1910" (Adorno, Vers une musique informelle, GS 16, p. 497) - justamente a época de ruptura com o tematismo, a época na qual Schoenberg escreveu Erwartung op. 17 e Die glückliche Hand op. 18. Acreditamos que, entre as tentativas de conceitualização de música informal, talvez a mais emblemática seja esta: música informal seria uma terceira via entre a "selva de Erwartung e a tectônica de Die glücklichen Hand", capaz de recolocar esses dois marcos da atonalidade livre em uma nova relação dinâmica (Adorno, Vers une musique informelle, GS 16, p. 531); ou seja, marcos anteriores à técnica dodecafônica. Em um pequeno artigo sobre Alban Berg, publicado quatro meses antes da conferência, Adorno esclarecia que Berg permanecia atual para o atual estágio da composição precisamente porque "desenvolveu, independentemente da técnica dodecafônica, procedimentos que se aproximam mais daquele impulso primário da atonalidade, de uma musique informelle, do que daquilo que a atonalidade (depois) racionalizou" (Adorno, Descobertas composicionais de Berg, GS 16, p. 415).

O impulso primário de ruptura da atonalidade fornece, nesse sentido, o modelo para a música informal, independentemente da técnica dodecafônica. $\mathrm{O}$ desenvolvimento da articulação entre construção formal e liberdade composicional dos anos 1910 teria sido interrompido, segundo Adorno, muito mais por fatores sociais e ideológicos (duas guerras, emergência da indústria cultural) do que por fatores imanentes à linguagem musical. O que Adorno defende como "tendência" em Vers une musique informelle seria, portanto, a retomada de um pensamento livremente atonal, porém sem passadismos, sem repetição de estilo ou "relaxamento da lógica da história". Essa tendência "a-serial" não ignora o serialismo, mas, reconhecendo seu estágio agônico, pretende superá-lo. Vale observar que o simples aggiornamento das aspirações do expressionismo não bastaria para definir o ideal utópico do programa. A referência à atonalidade livre, transposta para o contexto pós-serial dos anos 1960, reestabelecia o horizonte crítico contra toda ontologia das formas musicais, mas sem abrir mão de categorias que viabilizariam precisamente sua crítica. Por isso, Vers une musique informelle pode ser considerado mais do que um texto de intervenção, mais do que a definição de um programa - musique informelle representaria, nas palavras de Mahnkopf, a metateoria de Filosofia da nova música. ${ }^{13}$

13 "Vers une musique é a meta-teoria de Filosofia da nova música, (livro) no qual o diagnóstico da racionalização antecipa o problema do serialismo, a partir da generalização do princípio da série dodecafônica; é também um texto filosófico fundamental, pois se empenha em reafirmar as principais categorias de seu pensamento musical: tempo, forma, material, sujeito, construção, composição, lógica, expressão, sentido" (Mahnkopf, 1998, p. 259). 
As origens da acepção de informe que Adorno emprega não são explicitadas, embora o termo fosse comum nas artes plásticas. Certamente, há reminiscências da art informel dos anos 1950, movimento radical de pintura não figurativa que se afastava do construtivismo geométrico e integrava a gestualidade corporal, o tachismo e a aplicação de materiais e texturas não convencionais à superfície da tela. ${ }^{14}$ No entanto, parece-nos mais condizente ao ideal proposto pelo ensaio a descrição de informe que encontramos em Degas dança desenho (1938), o pequeno livro de Paul Valéry muito admirado por Adorno:

Eu pensava às vezes no informe. Há coisas - manchas, massas, contornos, volumes - que têm, de alguma maneira, somente uma existência de fato: são percebidas por nós, mas não conhecidas; não podemos reduzi-las a uma lei única, deduzir seu todo da análise de uma de suas partes, reconstruí-las por meio de operações racionais. Podemos modificá-las com bastante liberdade. Elas não têm outra propriedade senão ocupar uma região do espaço... Dizer que são coisas informes é dizer não que não têm formas, mas que suas formas não encontram em nós nada que permita substituí-las por um ato de traçado ou reconhecimento nítido. E, de fato, as formas informes não deixam outra lembrança senão a de uma possibilidade... ${ }^{15}$ (Valéry, 2012, pp. 78-79).

Valéry ilustra aqui um elemento essencial para o conceito adorniano: o informe não é a ausência de formas, mas a singularidade formal inscrita na própria coisa. É a individualidade da obra marcada por certo nominalismo em sua confrontação com esquemas abstratos. Pelo informal, prevalece uma concepção que não mais opõe o universal da forma preestabelecida e o elemento particular irredutível; uma objetividade que se esgota no interior da obra e abandona qualquer pretensão de universalidade abstrata e heterônoma. Evita-se, com o informal, tanto a "má universalidade" de fórmulas gastas quanto a absolutização do elemento particular. Adorno não pretende fundar uma "estética do ideal de expressão", atribuindo a primazia do comportamento mimético à dimensão construtiva. Na tendência em que se confronta dialeticamente esquemas externos, a composição deveria construir de modo objetivo sua própria substância, a qual "não podemos reduzir a uma lei única, deduzir seu todo da análise de uma de suas partes", como afirma Valéry.

A mediação do informe seria, portanto, a expressão da estrutura da objetividade musical através do sujeito e não contra ele (Adorno, Vers une

14 Entre os principais representantes, poderíamos citar Jean Dubuffet e Jean Fautrier, na França, e Bernhard Schultze, na Alemanha; nos Estados Unidos, seria equivalente ao "expresionismo abstrato", de Jackson Pollock, Willelm de Kooning, Mark Rothko. Cf. Borio, 1993, pp. 83-84.

15 De fato, não encontramos em lugar nenhum da produção adorniana referências à descrição do informe em Valéry. Entretanto, a referência não nos parecerá extravagante se considerarmos que esse pequeno livro sobre Degas foi o tema central do ensaio de 1953, O artista como representante, incluído em Notas de literatura I (Adorno, GS 11, p. 114). 
musique informelle, GS 16, p. 495). Recuperar essa dimensão subjetiva e "orgânica" envolve seguir os impulsos não sistemáticos, não mecânicos, do material. Nessa reflexão sobre os procedimentos convencionais, permanece incerto o resultado: "a vanguarda exige uma música que pegue o compositor de surpresa [...] seria a ideia de algo não totalmente imaginado" (Adorno, Vers une musique informelle, GS 16, p. 523); "a utopia artística hoje é fazer coisas que não sabemos o que são" (p. 540). ${ }^{16}$ Se Adorno não fornece as prescrições que seriam aguardadas de um manifesto, é porque a música informal, regime de renovação do material no próprio ato de composição, por definição inibe definições.

Esse regime, é preciso reiterar, não leva à "liquidação" abstrata das categorias tradicionais. De fato, Adorno admite que categorias como "antecedente e consequente, campos de tensão e repouso, progressão, desenvolvimento, contraste, afirmação" (Adorno, Vers une musique informelle, GS 16, p. 505) não poderiam mais ser tomadas a priori. Mas - e este "mas" cumpre função primordial no ensaio - caberia à música informal propor a criação de "equivalentes" (Äquivalente) dessas antigas categorias que fossem adequadas ao novo material, a fim de reestabelecer o sentido das diversas possibilidades que o habitam. Se, por um lado, falar em "sentido" nessa época dava impressão de reacionarismo romântico, por outro, o que estava em questão era a própria razão de existir da arte. ${ }^{17} \mathrm{E}$ dela dependia a "busca de equivalentes", isto é, a transformação de categorias tradicionais tanto de análise quanto de composição. Afinal, para ser mais do que "aglomerado de notas" (Tonhaufen), a música não deveria prescindir de categorias capazes de fornecer "articulação" (Artikulation) imanente ao próprio tempo da obra (Adorno, Vers une musique informelle, GS 16, p. 505). Adorno propõe, em Vers une musique informelle, essa transformação das categorias tradicionais através de uma "teoria material das formas" (materiale Formenlehre) - teoria esta que foi definida posteriormente pelo compositor György Ligeti como a "contribuição mais importante para uma teoria histórica das formas". ${ }^{18}$

16 Essa frase, que encerra Vers une musique informelle, remete explicitamente à epígrafe do ensaio - "Dire cela sans savoir quoi" ("Dizer isso, sem saber o quê") - do romance O inominável, de Beckett.

17 "Cegueira contra o sentido (Sinn) ou renúncia ao sentido em geral na mera atividade, tem se tornado tão difundido que simplesmente lembrar do sentido se torna suspeito de um reacionarismo romântico, quando na realidade o que se faz é uma reflexão da razão de ser da arte" (Adorno, Critérios da nova música, GS 16, p. 182).

18 "O aspecto histórico da forma foi analisado em profundidade por Adorno. Chamo a atenção em particular para o livro que dedicou a Mahler, a contribuição mais importante para uma teoria histórica das formas" (Ligeti, 2001, p. 143). 


\section{Teoria material das formas: a categoria de variante em Mahler}

Embora Adorno não desenvolva sua teoria material em Vers une musique informelle, o filósofo indica que esta seria a matriz para o engendramento dos "equivalentes" das categorias tradicionais. Podemos afirmar - juntamente com Borio, Paddison e Danuser ${ }^{19}$ - que a teoria não só está na origem da ideia de música informal como também é seu correlato no plano da análise musical. Em uma nota de rodapé de Vers une musique informelle, Adorno remetia a descrição de sua "teoria material das formas" à monografia sobre Mahler, publicada justamente no ano anterior. A monografia sugeria um modelo de compreensão adequado aos "gestos composicionais" e "caracteres fisionômicos" das obras de Mahler. Coexistindo com a teoria tradicional, essa teoria material forneceria categorias cuja validade deveria estar limitada à imanência da obra. Recusava, com isso, lançar uma estrutura conceitual prévia sobre o objeto. No caso de Mahler, para a descrição de seus "gestos composicionais", Adorno criava categorias como "variante" (Variante), "suspensão" (Suspension), "ruptura" (Durchbruch), "preenchimento" (Erfüllung), "recorrência modificada". No capítulo sobre os "caracteres" de Mahler, o autor expõe textualmente a teoria que deveria "fazer a música falar":

A partir de categorias como "suspensão" ou "preenchimento" nasce uma ideia cujas implicações vão além dos limites de sua obra. Essa ideia poderia contribuir para fazer a música falar por meio da teoria: a ideia de uma teoria material das formas, ou seja, de uma dedução de categorias formais a partir de seu sentido (no contexto da obra). A teoria acadêmica das formas passa ao largo dessa teoria material na medida em que opera com a ajuda de classificações puramente abstratas - como a que distingue "tema principal", "ponte", "tema secundário", "tema conclusivo" - sem que essas divisões sejam concebidas segundo sua função. Em Mahler, categorias concretas se superpõem às categorias abstratas convencionais (Adorno, Mahler, GS 13, pp. 193-194).

$\mathrm{Na}$ aplicação de equivalentes formais, a teoria material permitiria restituir a unidade de sentido dos processos composicionais. Não se trata, portanto, de um "repositório" de categorias de tipo esquemático ("tema principal", "tema secundário", "coda" etc.), ainda que tais categorias permitam estabelecer uma

19 Ver comentário de Borio: "aquilo que a música informal é no plano composicional possui um análogo na teoria musical: a teoria material das formas" (Borio, 2006, p. 61); ou ainda, Paddison: "[...] the origins of Adorno's concept of musique informelle are clearly to be seen in his 'material theory of musical form'" (Paddison, 1993, p. 182). Já Danuser redigiu um ensaio específico sobre a contribuição da teoria material de Adorno ao pensamento musical contemporâneo, a partir de uma reavaliação dessa teoria encaminhada em Mahler e TE à luz da dialética entre forma e material e dos tipos expressivos e sociais de sua filosofia. Cf. Danuser, 2007. 
primeira camada de sentido. A universalidade que subjaz aos equivalentes só adquire sentido em contato com a particularidade da obra; sem referência à obra, os equivalentes seriam insignificantes. Para Adorno, são os gestos composicionais de Mahler que, modificando funções previstas do material, inspiram a teoria. Gêneros e tipos formais estereotipados como marcha, valsa, sonata, rondo, scherzo são reconfigurados no interior de suas obras, de modo que não só a obsolescência desse material é colocada em primeiro plano como também suas fissuras, "o caráter fragmentário que está abaixo da unidade aparente das convenções tradicionais" (Paddison, 1993, p. 275). Na visão de Adorno, aí estariam os "criptogramas da modernidade" da escrita mahleriana. Em que pese o anacronismo do material, seu deslocamento qualitativo quebra expectativas previstas nos esquemas, desintegrando a forma à medida que a afirma. Desse modo, Mahler incorpora a um só tempo a dimensão normativa da forma e a crítica a ela: familiar e estranho se condensam.

Para que possamos compreender o alcance da teoria material das formas para o conceito de música informal, vale examinar a categoria material de variante, que Adorno cria para compreender o trabalho temático nas sinfonias de Mahler. Em oposição ao princípio tradicional de variação, a categoria de variante explicaria o caráter singular da formação dos temas em Mahler. Lembremos que o procedimento tradicional de variação efetua-se a partir de um tema original, cuja estabilidade seria dada por suas relações motívicas internas. Essa estrutura identitária do tema necessita ser preservada para que ocorram, afinal, múltiplas alterações em seu desenho melódico, padrão rítmico, timbrístico, de registro etc. ${ }^{20} \mathrm{O}$ princípio de variação fundamenta-se em uma lógica dedutiva: expõem-se as ideias essenciais, que, em seguida, são submetidas a desenvolvimentos. Em Mahler, contudo, o processo de formação temática extrapola o princípio de variação a ponto de torná-lo não mais reconhecível. Ou seja, não há mais distinção entre um original e uma variação do tema: a identidade do tema se volatiza em suas variantes. O conceito de tema, como "algo posto de modo determinado (eines bestimmt Gesetzten) e em seguida modificado, não convém a Mahler" (Adorno, Mahler, GS 13, p. 235). Seu trabalho composicional passa a privilegiar o dinamismo da formação temática e não mais seu resultado. Se não há um "original”, cada nova apresentação do tema seria um "original", de conteúdo motívico móvel, que não encontra configuração clara, positiva, definitiva: "as variantes expropriam (enteignen) do tema a sua identidade" (Adorno, Mahler, GS 13, p. 236), restando dele apenas emoldura suas 30 variações. 
um "vulto", uma figura genérica (Gestalt), que suas diferentes instâncias dão corpo. Se quisermos ainda falar em identidade do tema, essa identidade deveria consistir no conjunto qualitativo de suas diferentes variações. $\mathrm{O}$ tema corresponde a suas variantes. Para Adorno, a técnica da variante de Mahler radicaliza-se no primeiro movimento de sua Nona sinfonia. A repetição da seção de exposição temática desse movimento é tão elaborada, em suas contínuas variantes, que a repetição da seção de exposição "é percebida espontaneamente como a primeira parte da seção de desenvolvimento; só retroativamente é que se esclarece o que deveria ser chamado de desenvolvimento" (Adorno, Mahler, GS 13, p. 300). Essa diversidade dos temas liga-se intimamente à articulação épica do tempo. Os temas em Mahler "não são mais indiferentes ao devir musical [...] eles obedecem a impulsos, tornam-se outros, se retraem, se expandem, envelhecem, modificando profundamente um elemento outrora fixo" (Adorno, Mahler, GS 13, p. 221). Essa técnica progressiva da variante é comparada ao "momento épico-romanesco de figuras sempre diferentes e ao mesmo tempo idênticas" (p. 234). Os temas assumem características de personagens da epopeia, cuja identidade não se estabiliza, em conformidade à tradição oral do narrador na qual cada apresentação elabora um traço diferente do personagem narrado. Como se Mahler estivesse à procura de uma composição "entre aspas", de um estilo "indireto" de composição, sua música narrativamente nos diz: "escutem, isto é um desenvolvimento" ou "era uma vez uma sonata" (Adorno, Mahler, GS 13, p. 244).

A técnica mahleriana da variante, enquanto crítica produtiva do princípio de variação temática feita pelo compositor na própria forma musical, estende-se aos demais elementos de seu idioma. Para Adorno, a técnica oferece o paradigma para as formas da escrita épica, na medida em que aderem às ruínas da linguagem tonal e produzem ao mesmo tempo um distanciamento destas (Adorno, Mahler, GS 13, p. 236). Isto é, a transformação crítica atinge inicialmente a elaboração temática, mas em seguida se aplica à orquestração, ao uso do contraponto, à arquitetura formal. Mahler não inventa modelos de orquestração, não inventa formas. Mas, por meio da extensão da técnica da variante, traços da música de concerto, da música popular, do Volkslied, do exotismo oriental (como a escala de tons inteiros nas Canção da terra), são assimilados negativamente. São apresentados em desintegração como kitsch, não possuindo compromisso com a evolução do material. A originalidade aqui reside em um gesto composicional que desnaturaliza as relações de esquemas preestabelecidos, fazendo o kitsch, a convenção, falar por si mesmo. As reminiscências dessa descrição com o estilo tardio de Beethoven não são casuais. 


\subsection{Invariantes: os "equivalentes" na música informal?}

Podemos dizer que as categorias que Adorno criou para traçar a fisionomia composicional de Mahler são instâncias paradigmáticas dos "equivalentes" no conceito de música informal: ${ }^{21}$ a categoria de variante em Mahler seria "equivalente" à (e mantém relação com a) categoria tradicional de variação. Se insistimos na centralidade dos "equivalentes" em Vers une musique informelle, é porque Adorno claramente deseja reabilitar o potencial crítico de categorias tradicionais em um contexto pós-serial, tal como já indicava em Critérios da nova música (1957). Pois, mesmo na música atemática, "as relações entre Agora e Depois não devem ser arbitrárias, devem estar legitimadas no curso do tempo, não simplesmente em razão da identidade matemática estática de suas partes constituintes" (Adorno, Critérios da nova música, GS 16, p. 224).

Adorno desejava reabilitar fundamentos como "consequência, antítese, novo ataque, transição, resolução" (Adorno, Critérios da nova música, GS 16, p. 224), sem os quais se desvanece a tensão dialética que marca o processo histórico de espiritualização da música. Dito de outro modo: se Adorno reconhece que "progressão, desenvolvimento, contraste, afirmação" não podem mais ser considerados categorias musicais a priori (Adorno, Vers une musique informelle, GS 16, p. 505), se reconhece que a obrigatoriedade de tais categorias entrou em colapso com o serialismo, ao mesmo tempo ressalta que, sem "equivalentes" de tais categorias, a própria música perde sua razão de ser. A criação de "equivalentes" corresponde, assim, a uma das exigências fundamentais tanto da teoria quanto da prática contemporâneas.

\subsection{Determinação e indeterminação: os extremos se tocam}

Para Adorno, nem a forma-momento, de Stockhausen, nem a "incorporação controlada" do acaso na $3^{a}$ sonata. de Boulez, contemplavam o ideal da música informal, na medida em que tais procedimentos permaneciam indiferentes a uma temporalidade cujos eventos estariam legitimados em seu decurso próprio. $\mathrm{Ou}$ seja, o pensamento serial de Stockhausen e Boulez - serialismo que, como vimos, seria a figura estática do conceito especulativo de tematismo - não atenderia ao preceito constitutivo de sucessão orgânica, preceito que, para Adorno, assegurava precisamente a possibilidade de uma autêntica experiência musical. Dito de outro modo, o serialismo descuidava da diferença entre forma intencional e

21 Assim como em Mahler, também em Berg se encontrariam modelos de "equivalentes" formais. No Primeiro Quarteto op. 3, Adorno observa a mediação (pela forma rondó no segundo movimento, por exemplo) do informe, de um material que se apresenta como resto não submetido à forma. Se a "microtécnica de restos" de Berg ainda opera com estruturas herdadas da tonalidade (sonata, rondó, pensamento temático), elas são expostas de tal modo que acabam perdendo sua função vetorial de ordenação. O princípio de variação temática não é seguido. A maior parte dos temas possui caráter flutuante, indefinido, de variações mínimas e de modificações rítmicas em torno do intervalo de segunda menor. Cf. Boissière, 1999, pp. 92-93. 
forma resultante. Mesmo em obras altamente organizadas, como a $3^{a}$ sonata, a discrepância entre o sentido produzido e o efeito percebido decorre do simples fato de que o ouvinte não possui acesso prévio às suas estruturas. Embora, no contexto de Vers une musique informelle, a crítica seja direcionada menos a Stockhausen e Boulez e mais a Herbert Eimert (pois este, segundo Adorno, falhava em detectar as implicações estéticas de uma distinção entre ciência e obra da arte), o serialismo em todas as suas manifestações recairia sob o mito da estaticidade: assim como o filósofo afirmava em relação a Stravinsky, o serialismo consistiria na "imagem de uma música em si estranha ao tempo (das Bild einer in sich zeitfremden Musik)" (Adorno, Vers une musique informelle, GS 16, p. 529). A ambição da "organização virtualmente total”, que procurava incorporar o acaso em seu processo constitutivo, desprezava a organicidade do não idêntico, do ainda não totalizado, de um resto que pertence à essência da obra de arte (Adorno, Vers une musique informelle, GS 16, p. 526). Para Adorno, em suma, o pensamento serial ou por parâmetros sequer enfrentava o dilema na relação entre forma temporal e conteúdo musical (Adorno, Vers une musique informelle, GS 16, p. 518).

Na música indeterminada de John Cage, por sua vez, a tautologia "um som é um som" implicava o descompromisso com qualquer superestrutura ou historicidade; o som, para Cage, possuiria "poderes metafísicos". A provocação da antiarte de Cage não foi desprezada por Adorno: "dispensar a antiarte como cabaré ou piada de alto nível seria tão falso quanto sua celebração" (Adorno, Vers une musique informelle, GS 16, p. 533). Cage teve o mérito de explicitar a crise do sentido e de definição mesma de obra de arte, realizando um "protesto à cumplicidade da música com a dominação da natureza" (Adorno, Vers une musique informelle, GS 16, p. 534). Na contramão de leituras que constatam em Cage a ausência de uma atividade sintética do sujeito, Adorno estava plenamente convencido de que mesmo o Concerto para piano, de Cage, fornecia um sentido a contrapelo, justamente no deliberado rigor de evitar articulações e interconexões (Adorno, Vers une musique informelle, GS 16, p. 536). A intenção de evitar toda intenção (a exemplo do uso da simbologia do I Ching como instrumento de "decisão" para as escolhas entre ruído e silêncio) fazia com que a antiarte fosse mais do que ela mesma. Mas, precisamente por essa intenção não revelada, por seu princípio de "não obstrução", de "não intencionalidade", de eliminação do "desejo do compositor", ${ }^{22}$ a antiarte fracassava. Sua passividade

22 De maneira semelhante a Adorno, Stockhausen procurava demonstrar nas conferências de Darmstadt em 1959 que a ambiguidade notacional de Cage define, contra a sua vontade, um campo restrito de possibilidades e que a indeterminação, uma vez inscrita na partitura, resulta de intenções e desejos composicionais. Cf. Iddon, 2013, p. 242. 
ambicionava colocar entre parênteses o pertencimento social e histórico de cada evento sonoro, mas a não historicidade do som é incompatível com seus pressupostos e suas formas de produção. A tentativa de neutralização social da antiarte recaía, assim, em um positivismo que aderia à heteronomia social, pois ceder "espontaneamente" àquilo que a realidade oferece é uma das cifras fundamentais da ideologia. A rejeição em bloco à ideia de sentido supõe que esse enfraquecimento do papel subjetivo se transforme em virtude estética. Ocorre que o achatamento das circunstâncias históricas do qual depende essa resignação diante do acaso esvaziava, para Adorno, o potencial crítico da arte. Como lembra Marc Jimenez, "entre as várias atitudes de tipo reacionário, Adorno denunciava aquela que pensa que o mesmo material sonoro pode ser utilizado indiferentemente da época e da sociedade; considerar que o artista é livre diante do material é negar a interação entre sujeito e sociedade" (Jimenez, 1973, p. 66).

Adorno percebia então que os extremos se tocavam, como, de resto, havia observado Ligeti (2001, p. 125): música serial e música indeterminada, embora antitéticas entre si, induzem a efeitos semelhantes em função da separação radical entre construção e percepção musical. Engendram um estado de permeabilidade absoluta entre o sons, de perda da sensibilidade dos intervalos. Se o serialismo extrapola a construção, tendendo à dissociação entre composição e material, a música da indeterminação simplesmente a rejeita. Enquanto na prática serial, “decompõe-se tudo até o parâmetro do som individual para então se reconstruir o todo" (Adorno, Vers une musique informelle, GS 16, p. 520), na indeterminação, em analogia ao action painting, reduz-se a obra a um "criptograma da ação direta" da realidade sonora, mero decalque da realidade. Em comum, ambas fundamentam-se na hipóstase do fenômeno acústico, na ideologia de que o som individual bastaria por si só: ambas se tornam estranhas ao sujeito e ao tempo esteticamente construído.

A música informal ambicionava a superação dessa antinomia, através da recuperação da dialética entre repetição e não repetição, entre identidade e não identidade das formas. Como procuramos mostrar no início deste artigo, "reconstruir a temporalidade na música era para Adorno a tarefa primária da musique informelle" (Borio, 1987, p. 166). Tratava-se de examinar criticamente o processo de "destemporalização do tempo" que caracterizava não só a reflexão filosófica (conforme a crítica elaborada no modelo "Espírito do mundo e história natural", de Dialética negativa), mas também a música contemporânea.

Por fim, valeria destacar a atualidade do conceito de música informal sobre a denominada "música pós-serial". Para tanto, questionamos, primeiramente, a leitura de Fredric Jameson, em $O$ marxismo tardio, a respeito do conceito 
adorniano de música informal e, em seguida, analisamos brevemente os procedimentos de dois compositores contemporâneos cujas práticas remetem diretamente a esse conceito adorniano.

\section{Música informal: um conceito pós-moderno?}

À primeira vista, não seria tão problemática a afirmação de Fredric Jameson de que o conceito de música informal "inclui uma revolta contra as irreversíveis necessidades do tempo estético, mudança e progresso modernistas" (Jameson, 1996, p. 318). Afinal, o conceito criticava os excessos formalistas do modernismo musical dos anos 1950 - crítica à ontologia baseada na ov́oía de um denominador de fase-duração em Stockhausen ou à assimilação estrutural do tempo e do acaso em Boulez. Além disso, o apelo de Adorno à retomada de gestos composicionais do período da atonalidade livre da década de 1910 contribuía para uma interpretação de que a música informal representaria uma "revolta contra as irreversíveis necessidades do progresso modernista" (Jameson, 1996, p. 318). Jameson avalia que tanto o conceito de modernismo quanto o conceito de indústria cultural teriam perdido sua validade crítica no estágio pós-industrial de financeirização do capital, a partir dos anos 1970 . Na medida em que a expansão da cultura passaria a agenciar setores primordiais da economia, mediante novas formas de inter-relação institucional entre os media e o progresso tecnológico, a própria esfera da circulação dos objetos culturais e dos objetos artísticos seria modificada. Nesse estágio, não apenas os produtos de entretenimento, mas também as obras de arte mais avançadas e radicais do alto modernismo, seriam absorvidas pela forma-mercadoria, exigindo o tratamento dos fenômenos culturais em termos de economia política. Assim, descartado o conceito de indústria cultural, uma vez que o conceito de modernismo também se enfraqueceria. Em outras palavras, a autonomia que guiava a modernidade estética teria fracassado como projeto emancipatório. ${ }^{23}$ Para Jameson, portanto, "o conceito de uma musique informelle já é extremamente pós-moderno", uma vez que admite certo "relaxamento da lógica da história" (Jameson, 1996, p. 318).

Notemos, entretanto, que dificilmente o ensaio adorniano daria margem para tal interpretação, pois, se uma "música da liberdade" encontraria seu paradigma em obras do período expressionista, não deveríamos disso deduzir a recuperação não mediada de estilos do passado: "música informal não é neutralismo cultural,

23 “Jameson characterizes Adorno's modernism as somewhat dated, particularly when he considers how even the most powerfully oppositional works associated with this movement have been coopted in the postmodern world to further the process of absolute commodification" (Pizer, 1993, pp. 142-143, 148). 
mas crítica do passado" (Adorno, Vers une musique informelle, GS 16, p. 525). Referendar o passadismo como solução para impasses do presente seria desprezar a dinâmica da história das formas musicais. A música informal não prescreve o abandono da autonomia modernista em direção a um "informal" pós-moderno, pois a evolução da técnica não necessariamente se coaduna com a dialética do material; como vimos, para Adorno, a análise de Mahler pretendia mostrar que técnica e material são conceitos distintos. Nesse sentido, é suspeita a qualificação de "excessivamente pós-moderno" ${ }^{24}$ para um conceito tão central na reflexão adorniana como "música informal". Embora Adorno tenha, de fato, questionado o próprio direito de existência da arte em um mundo colonizado pela exterioridade do valor de troca e pela supressão da subjetividade, a categoria de autonomia não é abandonada. Ao recusar a falsa totalidade do hiperformalismo das práticas seriais, bem como a "má universalidade" (schlechte Allgemeinheit) de formas ontologizadas do passado, Adorno procurava repor um ideal utópico ainda associado ao modernismo. Não estava em questão o "relaxamento da lógica da história", como sugere Jameson, pois não estava em questão demolir os alicerces materialistas da teoria estética. Embora reconhecesse a situação aporética da obra de arte, Adorno salientava que, ao evitar as dificuldades técnicas da análise imanente das obras, da sua estrutura micrológica, limitandose apenas às esferas da distribuição e do consumo, o crítico sancionaria de antemão "a precedência da dimensão mercadológica da música” que justamente deveria desmistificar (Adorno, 1980, p. 263), eliminando a primazia do objeto. A constatação do pós-moderno como momento de completa espacialização da experiência do tempo talvez se solidarizasse à crítica adorniana da estaticidade musical. No entanto, o que Adorno atribui à estaticidade seria uma tendência de progressiva racionalização do material, e não a disposição sincrônica de formas e estilos do passado. ${ }^{25}$ Por isso, com o conceito materialista de música informal, estaria em curso a reafirmação em 1961 do próprio modernismo musical. Nesse sentido, seria interessante recordar o aforismo de Minima Moralia a respeito da dimensão qualitativa da obra modernista:

24 Cf. Kaufman, 2000, p. 720: "Vers une musique informelle considers what was then being called musique informelle and has since been deemed the New Music's entry into postmodernism; Adorno discusses John Cage, Olivier Messiaen, Herbert Eimert, and others, particularly in relation to second Viennese school modernism. [...] As might be predicted, Vers une musique informelle is filled with reflections on the constructionist heritage, but also (as Jameson rightly notes) with a perhaps surprising sympathy for the postmodernists' retreat from late constructivist hyperformalism."

25 "A relação mais crucial da música com o pós-moderno certamente passa pelo próprio espaço"; a MTV como modelo da 'espacialização da música'. Cf. Jameson, Pós-modernismo. A lógica cultural do capitalismo tardio, p. 304. 
[...] Modernidade é uma categoria qualitativa, de modo algum cronológica. Por menos que aceite a formulação abstrata, ainda necessita da renúncia à superficialidade convencional, à aparência de harmonia, à ordem fortalecida pela mera figuração [...] (Adorno, 2008, afor. 140, "Culminação dos tempos").

Com a música informal, Adorno não infere um salto da noção de modernidade para fora da história. Antes, concebe a modernidade uma conquista histórica da qual todo objeto que aceda à condição de arte não deveria abrir mão. $\mathrm{O}$ modernismo, afinal, como "mito voltado contra si mesmo", como "história do esforço pela maioridade"26 (seguindo a referência kantiana), história sedimentada a partir da cisão moderna da subjetividade, parece não ter atingido (hoje, pelo menos) seu estágio de completa exaustão no torvelinho cultural do capitalismo financeirizado e transnacional. Ainda que se cogite a possibilidade de a estética modernista se converter em mero necrológio da arte, ${ }^{27}$ o exemplo da música informal comprova que ainda haveria um longo caminho a ser percorrido. Nesse contexto, valeria uma última digressão a respeito de algumas vertentes da música dita "pós-serial", que buscam, em certa medida, se aproximar do programa de uma música informal.

\subsection{Lachenmann e Rihm}

Sabemos que a história do serialismo não convém a narrativas unívocas: a vanguarda dos anos 1950 e 1960 esteve marcada por sobressaltos e inconsistências, que resultavam da formulação frequente de novas técnicas e novas abordagens. O que se sabe é que o ano de 1968, além de ter ramificado novas formas de subjetivação política com as aspirações de Maio, marcou também o fim de uma era de experimentações baseadas na "força de lei" do pensamento serial e baseadas na repulsa às formas musicais tradicionais. Ocorre que também a música "pós-serial", com sua complexa rede de relações, inibe a concepção de uma narrativa linear. Apesar disso e dos riscos da má interpretação, arrisquemos, no entanto, um olhar de sobrevoo sobre dois compositores que procedem de vertentes contraditórias da música pós-serial, mas que procuram a retomada de formas do passado e a antiga tensão entre regra e emancipação da regra: Helmut Lachenmann e Wolfgang Rihm.

Lachenmann, que foi assistente de Luigi Nono e aluno de Stockhausen, afastou-se das imposições do serialismo nos anos 1960. Sua poética nasce da

26 Ver as passagens de Teoria estética, GS 7, p. 41: "O moderno é um mito voltado contra si mesmo; sua intemporalidade torna-se catástrofe do instante que rompe a continuidade temporal". E também GS 7, pp. 7071: "A história do moderno é uma história do esforço pela maioridade (eine der Anstrengung zur Mündigkeit)."

27 "Ästhetik heute hat keine Macht darüber, ob sie zum Nekrolog für die Kunst wird" (Adorno, Teoria estética, GS 7, p. 13). 
exploração acústica dos instrumentos da orquestra tradicional, de sonoridades que, segundo o compositor, foram "recalcadas" como inadmissíveis na prática interpretativa. A obra deseja, nesse sentido, integrar à composição os sons "secundários" que os intérpretes necessariamente produzem ao tocar um instrumento, como os que resultam da pressão do arco e do escorregar dos dedos sobre as cordas, a respiração, os sussurros nos instrumentos de sopro, as reverberações não intencionadas e rechaçadas pelos padrões culturais do ocidente - uma poética que, segundo o compositor, pretendia construir uma "música concreta instrumental". ${ }^{28}$ Em peças como Pression (1970), para violoncelista solo, e Guero (1970/1988), para piano, desvenda-se um espaço sônico amplo dos instrumentos, indo além de parâmetros como altura e duração e transformando em objetos sonoros de composição aquilo que tradicionalmente denominamos "ruídos". Lachenmann cria novas formas musicais cuja inteligibilidade se dá na percepção das condições físicas, das energias e resistências mecânicas envolvidas no próprio gesto de produção do som. ${ }^{29}$ Em Accanto (1976-77), propõe um conceito de "desfamiliarização" da música tradicional que traz implicações excêntricas à compreensão do conceito de forma. Nessa peça escrita para clarinete e orquestra, surgem alusões - às vezes subliminares, às vezes escancaradas - ao Concerto para clarinete em lá maior, de Mozart. Essas sonoridades, porém, estão de tal modo constituídas e se encontram a tal ponto deslocadas de suas funções usuais que as referências ao concerto de Mozart assumem um aspecto incômodo na peça, soando como se fossem ruídos. Em uma inversão inesperada, essas referências abandonam sua feição de cânone ocidental e se apresentam explicitamente como elementos de exceção na obra. Parecem, com isso, perder a familiaridade decorrente de sua propagação enjoativa pela indústria cultural - diga-se de passagem que se trata de um procedimento bastante diverso da fusão arbitrária ou paródica da montagem e das citações musicais.

Assim como Lachenmann, Wolfgang Rihm também frequentou os cursos de Kranichstein-Darmstadt e foi aluno de Nono e Stockhausen. Considerado um dos representantes do "neorromantismo" ou "neoexpressionismo" contemporâneo, Rihm reintroduz modelos de uma retórica expressiva tradicional que tinham sido proscritos pela cartilha serial nos anos 1950. Sua expressividade vincula-se confessadamente a Mahler e à atonalidade livre dos anos 1910, mas tensiona a

28 'Lachenmann derived the notion of 'musique concrète instrumentale' from Pierre Schaeffer's concept, originating in the 1940s, of 'musique concrète' - music that deploys recorded sounds as opposed to electronically generated sounds" (Williams, 2013, p. 76).

29 No prefácio da partitura de Pression, podemos ler: "Except for places where pitches are notated in the traditional manner, the notation of this piece does not indicate the sounds, but the player's actions." (Williams, 2013, p. 79). 
preexistência dessa retórica com as instabilidades formais que sempre estiveram em sua origem e que foram, por assim dizer, sublimadas pela tradição. É nesse sentido que Rihm afirma seguir o programa adorniano da música informal: ambiciona dissolver categorias da música tradicional, reinventando o escopo expressivo dessas mesmas categorias. Não sem algum quixotismo, Rihm chegou a declarar nestes termos sua admiração por Vers une musique informelle: "Leio com bastante frequência esse texto e desde o início tive a sensação de ser diretamente convocado por ele; parece que foi direcionado para mim". ${ }^{30}$ Tal influência torna-se explícita no título da série de suas peças sinfônicas Vers une symphonie fleuve I-IV (1992-1998). Por um lado, a ênfase no trabalho timbrístico, na criação de continuidades através do contraste gradual das texturas - procedimento típico da música pós-serial, como em Atmosphères, de Ligeti -, não impede que Rihm também dialogue com a tradição do pensamento motívico-temático, anterior ao serialismo. Sua música incorpora células rítmicas previsíveis, figuras melódicas e progressões harmônicas tonais, ainda que interrompidas ou expostas de maneira nostálgica. Embora as formas que utiliza não obedeçam a esquemas, expõem claramente um sentido progressivo. Esse sentido, por assim dizer fluido, é fornecido, em Vers une symphonie fleuve, por dinâmicas progressivas nas cordas, intensamente carregadas de expressão, e ruídos percussivos massivos que se amplificam no decorrer da peça, como se a obra tivesse seguido uma ramificação, uma linha específica de desenvolvimento, uma entre outras linhas possíveis, a partir de uma matéria sonora inicial. A técnica confere extensão temporal e direcionalidade que não existiam na atonalidade livre, o universo sonoro de referência para o compositor. Por outro lado, definida como work in progress, cada uma dessas peças sinfônicas expande o material da peça precedente, seguindo outras linhas de desenvolvimento e exigindo eventualmente a alteração retroativa da linha escolhida previamente - o que não raro faz com que o compositor revise partituras já publicadas, executadas e gravadas. Assim, mesmo que os modelos expressivos de Vers une symphonie fleuve sejam bastante convencionais, o compositor empenha-se, tanto quanto Lachenmann, em desvendar possibilidades formais de estranhamento, dada pela exploração de uma matéria sonora inicial qualquer.

Para ambos os compositores, não se trata mais de simplesmente recusar as formas do passado, como ocorria na atonalidade livre e no serialismo, mas de reagir historicamente a uma instabilidade intrínseca dessas mesmas formas; uma instabilidade tomada como inevitável desde o início; uma instabilidade cuja 
provisória cristalização sempre depende do momento específico de produção e que, assim como as formas informes de Valéry, "não deixa outra lembrança senão a de uma possibilidade".

\section{Referências}

ADORNO, T. W. “Gesammelte Schriften in 20 Bänden”. Frankfurt am Main: Suhrkamp Verlag, 1986; Berlin: Directmedia-Surkhamp [Digitale Bibliothek, CD-ROM], 2003. (Edição citada como GS, seguido do número do volume e da página correspondente). . "Ideias para a sociologia da música". In: Adorno (coleção "Os pensadores"). Tradução de Roberto Schwarz. São Paulo: Abril Cultural, 1980.

. "Minima Moralia: reflexões a partir da vida lesada". Tradução de G. Cohn. Rio de Janeiro: Azougue Editorial, 2008.

ALMEIDA, J. "Crítica dialética em Theodor Adorno: música e verdade nos anos vinte". São Paulo: Ateliê Editorial, 2007.

BOISSIÈRE, A. "Adorno: la vérité de la musique moderne". Villeneuve d'Ascq: Presses Univ. Septentrion, 1999.

BORIO, G. "Die positionen Adornos zur musikalischen Avantgarde zwischen 1954 und 1966». In: Adorno in seinen musikalischen Schriften. Regensburg: G. Bosse, 1987.

."'Dire Cela, Sans Savoir Quoi': The Question of Meaning in Adorno and in the Musical Avantgarde". In: Apparitions: New Perspectives on Adorno and Twentieth Century Music. Org. Berthold Hoeckner. New York: Routledge, 2006.

."Musikalische Avantgarde um 1960: Entwurf einer Theorie der informellen Musik". Laaber: Laaber-Verlag, 1993.

DANUSER, Hermann. “"Materiale Formenlehre' - ein Beitrag Theodor W. Adornos zur Theorie der Musik". In: Musikalische Analyse und Kritische Theorie: zu Adornos Philosophie der Musik. Org. Adolf Nowak; Markus Fahlbusch. Tutzing: Hans Schneider, 2007.

EIMERT, H. "What is electronic music?" In: Die Reihe \#1 - Electronic Music (eng. edition). Pennsylvania: Theodore Presser, 1958. Vol. 1.

GEUSS, R. "Morality, Culture, and History: Essays on German Philosophy”. Cambridge: Cambridge University Press, 1999.

IDDON, M. "New music at Darmstadt: Nono, Stockhausen, Cage, and Boulez". Cambridge; New York: Cambridge University Press, 2013.

JAMESON, F. "O marxismo tardio: Adorno ou a persistência da dialética". Tradução de Luís Paulo Rouanet. São Paulo: Ed. Unesp, 1996.

JIMENEZ, M. "Theodor W. Adorno: art, idéologie et théorie de l'art". Paris: Union générale d'éditions, 1973.

KAUFMAN, R. "Red Kant, or the Persistence of the Third 'Critique' in Adorno and Jameson". Critical Inquiry, v. 26, n. 4, 2000.

LIGETI, G. "Évolution de la forme musicale (1960)". In: Neuf essais sur la musique. Tradução de Catherine Fourcassié. Genève: Contrechamps Éditions, 2001. 
."La forme dans la musique nouvelle". In: Neuf essais sur la musique. Tradução de Catherine Fourcassié. Genève: Contrechamps Éditions, 2001.

MAHNKOPF, C.-S. "Adornos Kritik der neueren Musik”. In: Mit den Ohren denken: Adornos Philosophie der Musik. Frankfurt am Main: Suhrkamp, 1998.

MÜLLER-DOOHM, S. “Adorno: A Biography”. Tradução de Rodney Livingstone. Cambridge: Polity, 2009.

PADDISON, M. "Adorno's aesthetics of music". New York: Cambridge University Press, 1993.

PIZER, J. "Jameson's Adorno, or, the Persistence of the Utopian". New German Critique, Nr. 58, p. 127, 1993.

SOCHA, E. "Tempo musical em Theodor W. Adorno". Tese de Doutorado, FFLCH/ Universidade de São Paulo, São Paulo, 2015.

VALÉRY, P. "Degas dança desenho". Tradução de C. Euvaldo; C. Murachco. São Paulo: Cosac Naify, 2012.

WIGGERSHAUS, R. "A Escola de Frankfurt: História, Desenvolvimento Teórico, Significação Política". Rio de Janeiro: Difel, 2002.

WILLIAMS, A. "Music in Germany since 1968". New York: Cambridge University Press, 2013. 